\title{
Myeloperoxidase Stain
}

National Cancer Institute

\section{Source}

National Cancer Institute. Myeloperoxidase Stain. NCI Thesaurus. Code C158245.

Immunohistochemical or enzyme cytochemical staining method to detect

myeloperoxidase, a lysosomal protein that has peroxidase enzyme activity and is present

in granulocytic and monocytic cells, but absent in lymphocytes. 